\title{
Application of EPR Spectroscopy to Examination of the Effect of Sterilization Process on Free Radicals in Different Herbs
}

\author{
Katarzyna Pawłowska-Góral • Pawel Ramos • \\ Barbara Pilawa • Ewa Kurzeja
}

Received: 17 April 2012 / Accepted: 16 January 2013 / Published online: 29 January 2013

(C) The Author(s) 2013. This article is published with open access at Springerlink.com

\begin{abstract}
Free radicals in the original and sterilized caraway, curry, curcuma and cardamom were studied. An Xband $(9.3 \mathrm{GHz})$ electron paramagnetic resonance (EPR) spectroscopy was the experimental technique. Effect of microwave power in the range of $2.2-70 \mathrm{~mW}$ on amplitudes, linewidths, and lineshape parameters of the EPR spectra was tested. Free radicals concentrations in the non- and sterilized herb samples were compared. The aim of this work was to determine properties and concentration of free radicals in steam sterilized caraway, curry, curcuma and cardamom. It was pointed out that free radicals $\left(\sim 10^{18} \mathrm{spin} / \mathrm{g}\right)$ exist in both the original and sterilized herbs. Complex free radical system with oxygen and carbon paramagnetic centers characterizes the examined herbs. Homogeneously dipolar broadened EPR spectra were measured for all the tested herbs. Slow spin-lattice relaxation processes exist in the examined samples. Practical usefulness of EPR method in food technology was discussed.
\end{abstract}

Keywords Herbs $\cdot$ Sterilization process $\cdot$ Free radicals $\cdot$ EPR spectroscopy

K. Pawłowska-Góral · E. Kurzeja

Department of Food and Nutrition, Medical University of Silesia

in Katowice, Jedności 8,

41-200 Sosnowiec, Poland

P. Ramos $(\varangle) \cdot$ B. Pilawa

Department of Biophysics, Medical University of Silesia

in Katowice, Jedności 8,

41-200 Sosnowiec, Poland

e-mail: pawelramos@sum.edu.pl

\section{Introduction}

During sterilization of the materials different physical and chemical factors interact with the samples [1,2]. They may disrupt chemical bonds in molecules of the sterilized materials and they may initiate chemical reactions. As the result of interactions of the sterilizing factors and the sterilized samples free radicals may appear. It is known that sterilization process forms free radicals in drugs [3-6]. Free radicals were detected in thermally sterilized aminoglycoside drugs [3] and in radiative sterilized by gamma irradiation antibiotics [5].

The other example of process of free radical formation in technology practice is sterilization of herbs. The aim of this work was to determine properties and concentration of free radicals in different sterilized herbs. Steam sterilization was chosen by the sterilization method. Free radicals properties in the original and sterilized herbs were studied. The usefulness of the performed method of sterilization of these herbs was checked by electron paramagnetic resonance (EPR) spectroscopy. It was expected that the low amount of free radicals was formed during sterilization process. Free radicals with unpaired electrons are highly reactive molecules and they may cause negative effects in human organism.

Free radicals in the tested herbs were not studied earlier. Free radical properties of the Rizoma calami [7] were examined spectrosocpically by us. The usefulness of EPR spectroscopy to evaluation of the sterilziation process of herbs was pointed out in our paper [7]. The practical conclusions about sterilization process of the studied herbs were drawn. 


\section{Experimental Method}

\section{The Studied Herbs}

The popular herbs as the caraway, curry, curcuma, and cardamom (Fig. 1) were studied. Caraway is cumin common, cumin grasshopper (Carum carvi), biennial of the Umbelliferae family, found in the wild in northern and central Europe, northern Africa and Asia. It spices and medicinal plant, widely grown $[8,9]$. Utility of caraway was known since ancient times. Since the beginning of historic times it was a meat and bread seasoning in medieval Europe. It is also used to treat stomach problems, diarrhea, flatulence, colic and as a diuretic [8,9]. Cumin seeds contain minerals, protein, sugars, organic acids, wax, oil, flavonoids and quercetin. They are also used for the production of vodka and in cosmetic industry as an added fragrance to soaps, creams or perfumes $[8,9]$.

Curry is a generic description used throughout Western culture to describe a variety of dishes from Indian, Pakistani, Bangladeshi, Sri Lankan, Thai or other Southeast Asian cuisines $[8,9]$. The chief spices found in most South Asian curry powders are turmeric, coriander and cumin; a wide range of additional spices may be included depending on the geographic region. Curry's popularity in recent decades has spread from Southern Asia to figure prominently in international cooking $[8,9]$.

Curcuma is a genus of about 80 accepted species in the plant family Zingiberaceae that contains such species as turmeric and Siam Tulip. The name comes from Arabic

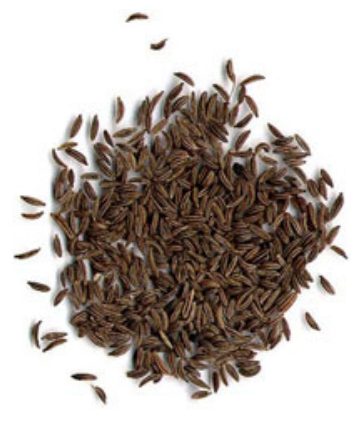

a

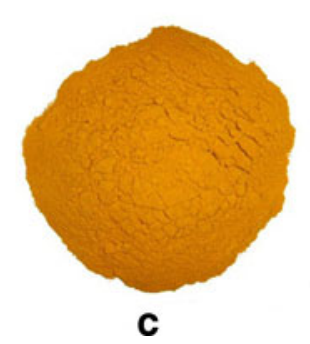

Fig. 1 The studied herbs: caraway (a), curry (b), curcuma (c), and cardamom (d) kurkum which means "turmeric" $[8,9]$. Since assembly of the genus Curcuma by Linnaeus in 1753 about 130 species have been described so far. Some of the species descriptions are without Latin diagnosis or type specimen, therefore the legitimate status of many species is suspicious and remains unclear $[8,9]$.

Cardamom is a rather large, long-term plant. It is a herb growing wild, as well as growing them in the fields of India $[8,9]$. Cardamom is one of the oldest spices in the world and has been used extensively in ancient Egypt for the production of perfume. Cardamom was known in ancient Greece where it was used as a medicine and to flavor dishes $[8,9]$. It was known as a cure for all kinds of digestive ailments, such as indigestion, flatulence, stomach cramps. Cardamom has a pleasant taste and is often used as an ingredient in medicines for digestive problems. Its delicate flavor helps to endure the taste of less palatable herbs $[8,9]$. Cardamom is used in India to cure a lot of diseases, such as asthma, bronchitis, kidney stones, lack of appetite and weakness. In China, cardamom is used to treat urinary incontinence and as a tonic. Cardamom is an effective means to get rid of bad breath $[8,9]$.

\section{Sterilization of the Herbs}

The material for the study was provided by K.P.P.S. Interjarek company (Gołuchów, Poland) where herbs and spices were sterilized by means of $\mathrm{NMC}^{\circledR} 89$ steam sterilization method.

\section{Sample Preparation to EPR Measurements}

The powdered samples of the original and the sterilized caraway, curry, turmeric, and cardamom were placed in the thin walled glass tubes with the external diameter of $3 \mathrm{~mm}$. Mass of these samples located in the tubes were measured. The empty tubes were free of the EPR signals at the applied receiver gains and microwave powers (up to $70 \mathrm{~mW}$ ).

\section{EPR Measurements}

\section{Conditions of EPR Measurements}

Paramagnetic properties of the samples will be examined by the use of electron paramagnetic resonance spectroscopy (EPR). Free radicals in the herb samples were searched and their properties were tested.

EPR spectra of the samples were measured by the use of an X-band $(9.3 \mathrm{GHz})$ electron paramagnetic resonance spectrometer produced by Radiopan Firm (Poznań, Poland). Magnetic modulation of $100 \mathrm{kHz}$ was used. To avoid microwave saturation EPR lines will be collected at low microwave power of $0.7 \mathrm{~mW}$ and high attenuation of $20 \mathrm{~dB}$. 

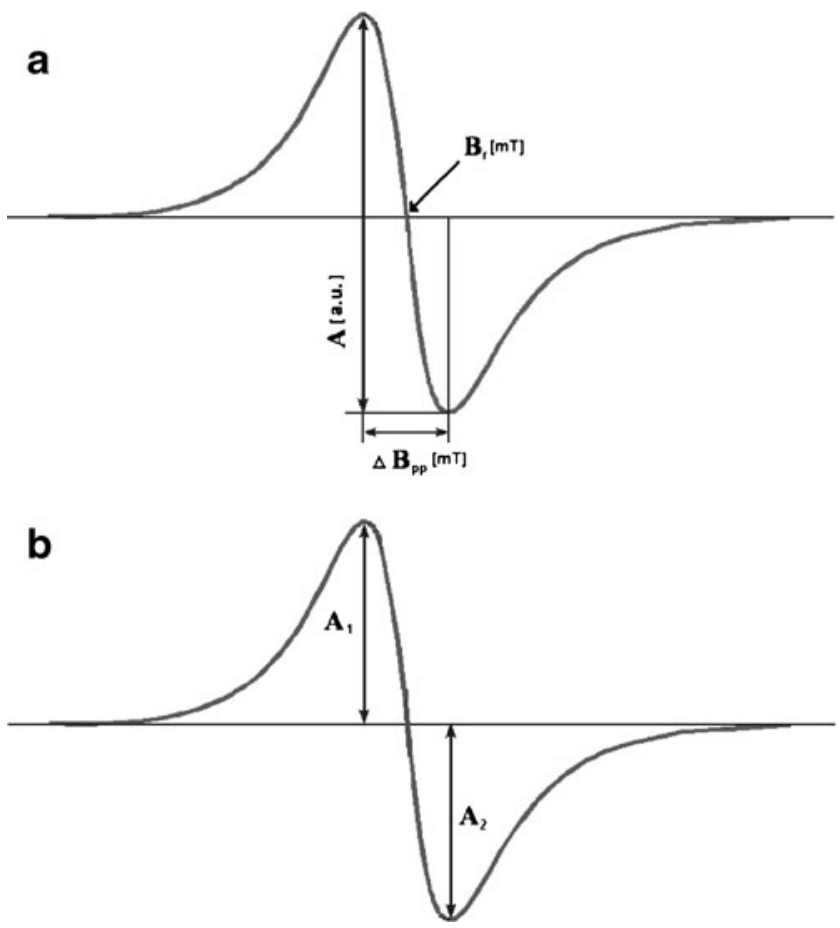

Fig. 2 The first derivative EPR spectrum with the parameters: amplitude (A), linewidth $\left(\Delta \mathrm{B}_{\mathrm{pp}}\right)$, and resonance magnetic field $\left(\mathrm{B}_{\mathrm{r}}\right)(\mathbf{a})$. The analysed lineshape parameters of the EPR spectra: $A_{1}$ and $A_{2}(b)$

\section{The Analysed Parameters of EPR Spectra}

For the original and the sterilized herbs the lineshape and the parameters of the EPR spectra were compared. For the
Table 1 Free radical concentration $(N)$ in the studied sterilized herb samples, and the EPR spectra parameters: g-factor, and linewidth $\left(\Delta \mathrm{B}_{\mathrm{pp}}\right)$. The data for the measurement with microwave of $2.2 \mathrm{~mW}$ at room temperature

\begin{tabular}{llll}
\hline Herbs & $\begin{array}{l}\mathrm{N} \times 10^{18} \\
{[\text { spin/g] }}\end{array}$ & $\begin{array}{l}\text { g-factor } \\
{[ \pm 0.0002]}\end{array}$ & $\begin{array}{l}\Delta \mathrm{B}_{\mathrm{pp}} \\
{[ \pm 0.02 \mathrm{mT}]}\end{array}$ \\
\hline Caraway & 2.84 & 1.9973 & 0.56 \\
Curry & 0.33 & 1.9953 & 0.62 \\
Curcuma & 0.32 & 1.9965 & 0.67 \\
Cardamom & 0.61 & 1.9961 & 0.65 \\
\hline
\end{tabular}

studied samples the following parameters of EPR spectra were analyzed: g-factors, amplitudes (A), integral intensities (I), and linewidths $\left(\Delta \mathrm{B}_{\mathrm{pp}}\right)$. Amplitude and integral intensity are dependent on paramagnetic centers concentration in the samples [10]. Linewidth reflects magnetic properties of the samples [10].

g-Values will be calculated from resonance condition according to the formula: [10]

$\mathrm{g}=\mathrm{h} v / \mu_{\mathrm{B}} \mathrm{B}_{\mathrm{r}}$

where:

h Planck constant,

$v$ microwave frequency,

$\mu_{\mathrm{B}}$ Bohr magneton,

$\mathrm{B}_{\mathrm{r}} \quad$ resonance magnetic field.

Microwave frequency $(v)$ was directly measured by MCM101 recorder produced by EPRAD Firm (Poznań,
Fig. 3 EPR spectra of caraway (a), curry (b), curcuma (c), and cardamom (d). The spectra were measured with microwave power of $2.2 \mathrm{~mW}$ at room temperature

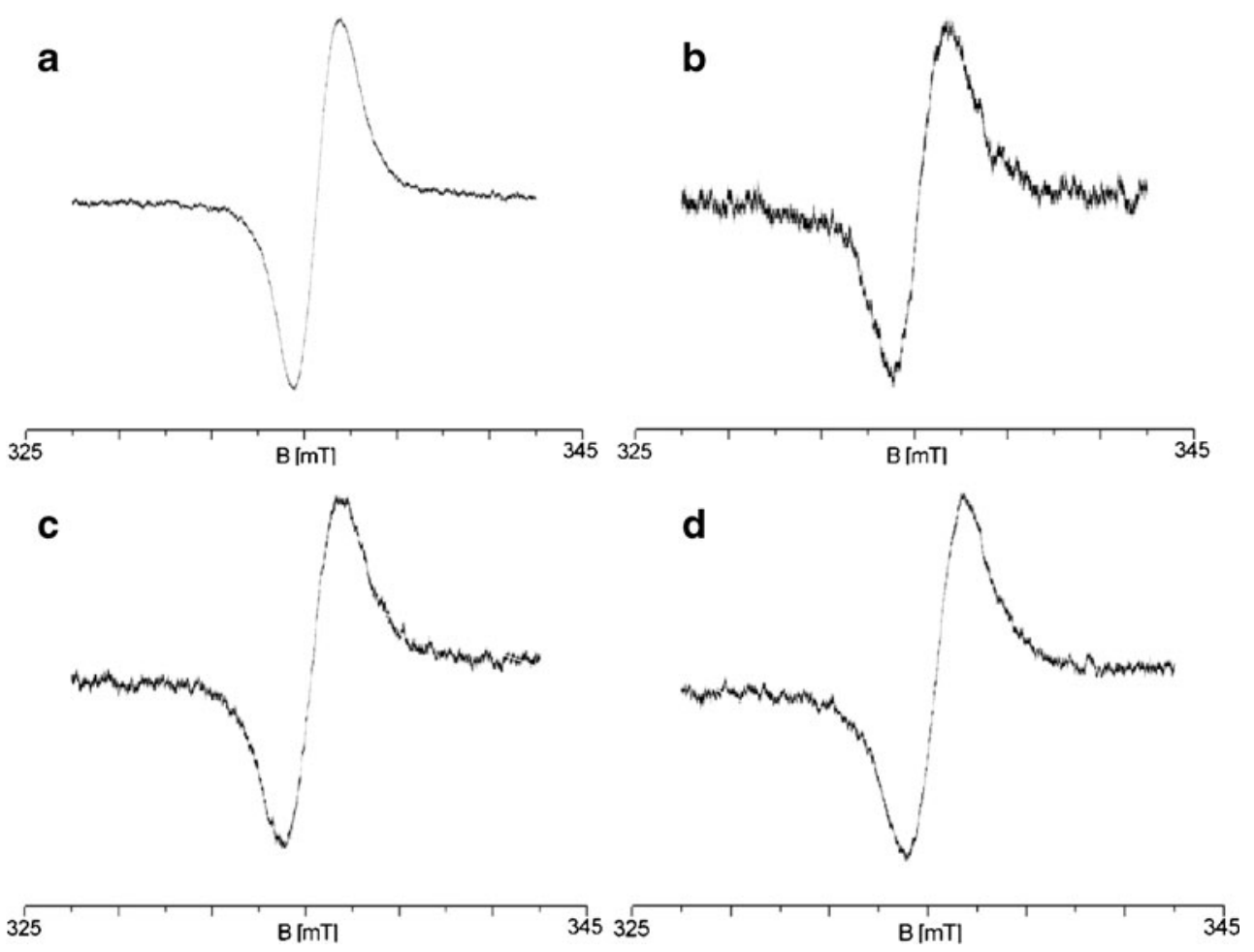


Fig. 4 Comparison of amplitudes (A) of EPR spectra of the studied original and sterilized herbs. The spectra were measured with microwave power of $2.2 \mathrm{~mW}$ at room temperature

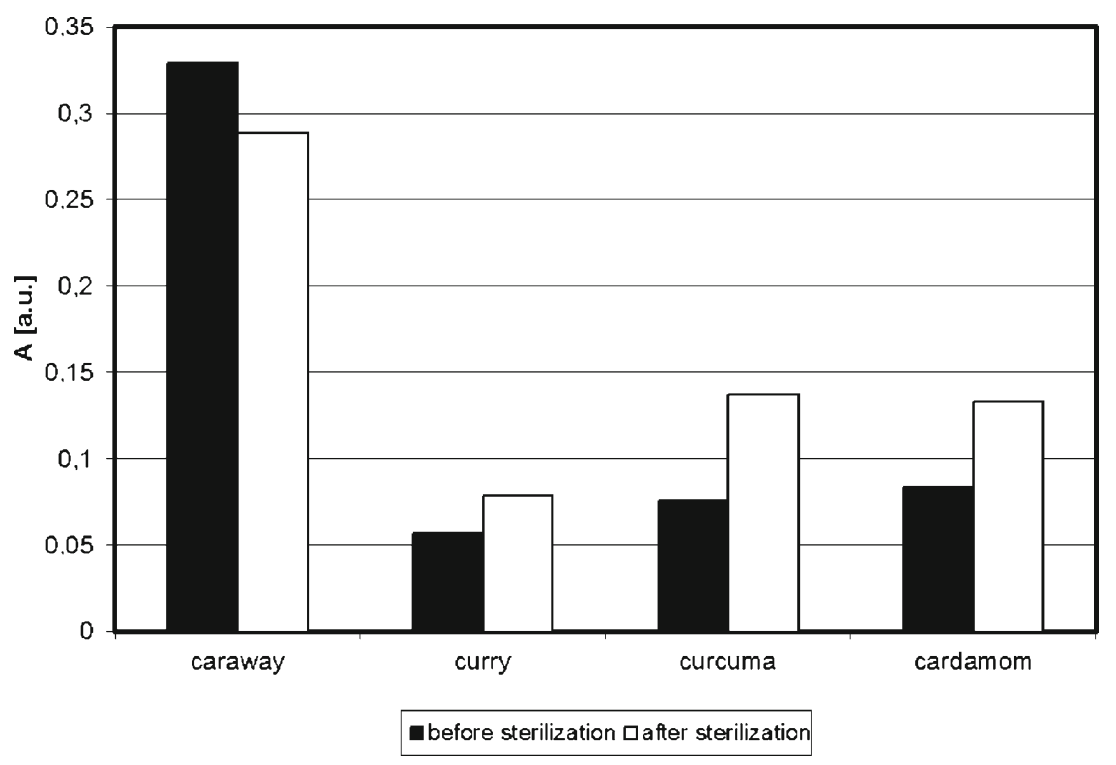

Poland). The $\mathrm{B}_{\mathrm{r}}$ value was determined from the electron paramagnetic resonance lines.

Influence of microwave power on the EPR spectra was examined. Changes of amplitudes (A), integral intensities (I), and linewidths $\left(\Delta \mathrm{B}_{\mathrm{pp}}\right)$ with microwave power in the range $0.7-70 \mathrm{~mW}$ were tested.

Spin-lattice relaxation processes in the samples were characterized by observation of microwave saturation of their EPR lines. Power of microwave saturation of EPR lines increases with fastening of spin-lattice relaxation processes [10].

\section{The Analysed Lineshape Parameters of EPR Spectra}

The parameter $A_{1} / A_{2}$ of lineshape of the EPR spectra was analysed. The values of $A_{1}$ and $A_{2}$ are presented in Fig. 2.
The lineshape parameter $A_{1} / A_{2}$ was determined for the EPR spectra recorded in the range of microwave power 2.2-70 $\mathrm{mW}$ to show the existence of several groups of free radicals in the samples. The changes of the shape of EPR spectra with microwave power were tested.

Determination of Free Radicals Concentration in the Herb Samples

Concentrations of paramagnetic centers $(\mathrm{N})$ in the studied samples were compared. The concentration was determined as the value proportional to the integral intensity (I) of EPR spectrum [10, 11]. The integral intensities were calculated by double integration of the first-derivative EPR spectra. Ultramarine was used as
Fig. 5 Comparison of linewidths $\left(\Delta \mathrm{B}_{\mathrm{pp}}\right)$ of EPR spectra of the studied original and sterilized herbs. The spectra were measured with microwave power of $2.2 \mathrm{~mW}$ at room temperature

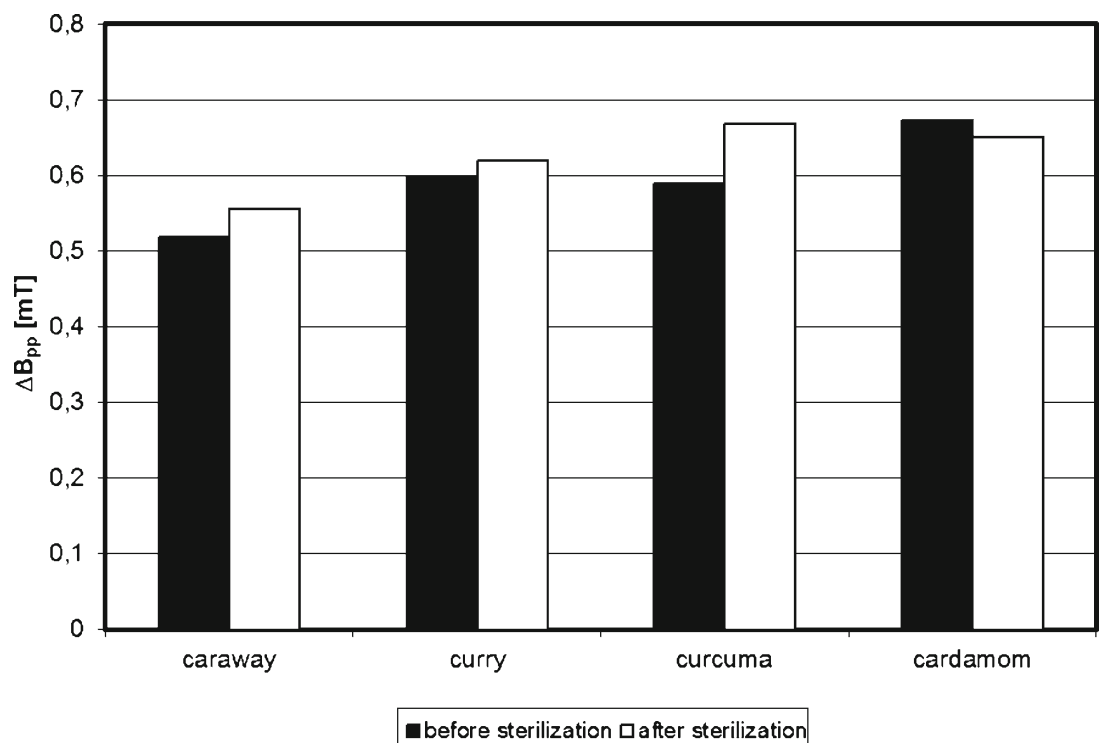


Fig. 6 Comparison of free radical concentrations $(\mathrm{N})$ in the studied original and sterilized herbs. The spectra were measured with microwave power of $2.2 \mathrm{~mW}$ at room temperature

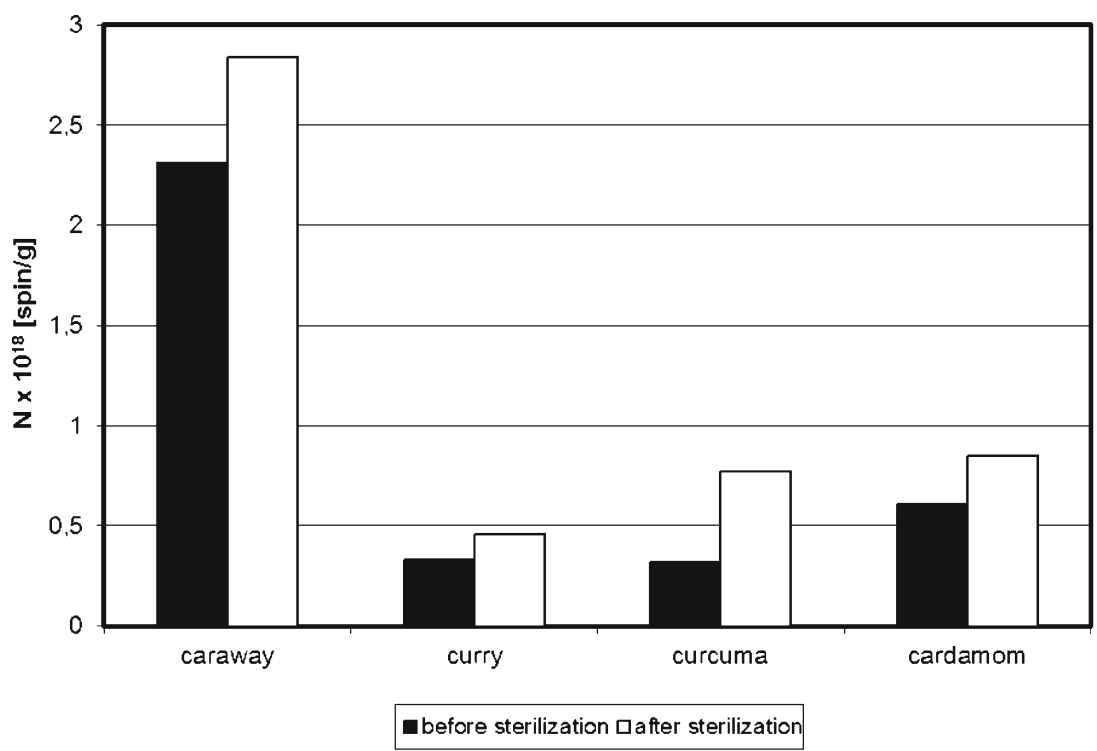

the reference for concentration of free radicals. To obtain the values of concentration the integral intensities of the spectra of the tested samples were compared to the integral intensity of the ultramarine spectrum. The second reference - $\mathrm{a}$ ruby crystal $\left(\mathrm{Al}_{2} \mathrm{O}_{3}: \mathrm{Cr}^{3+}\right)$ was permanently placed in a resonance cavity. For each sample and for the reference-ultramarine the EPR line of a ruby crystal was detected with the same receiver gain
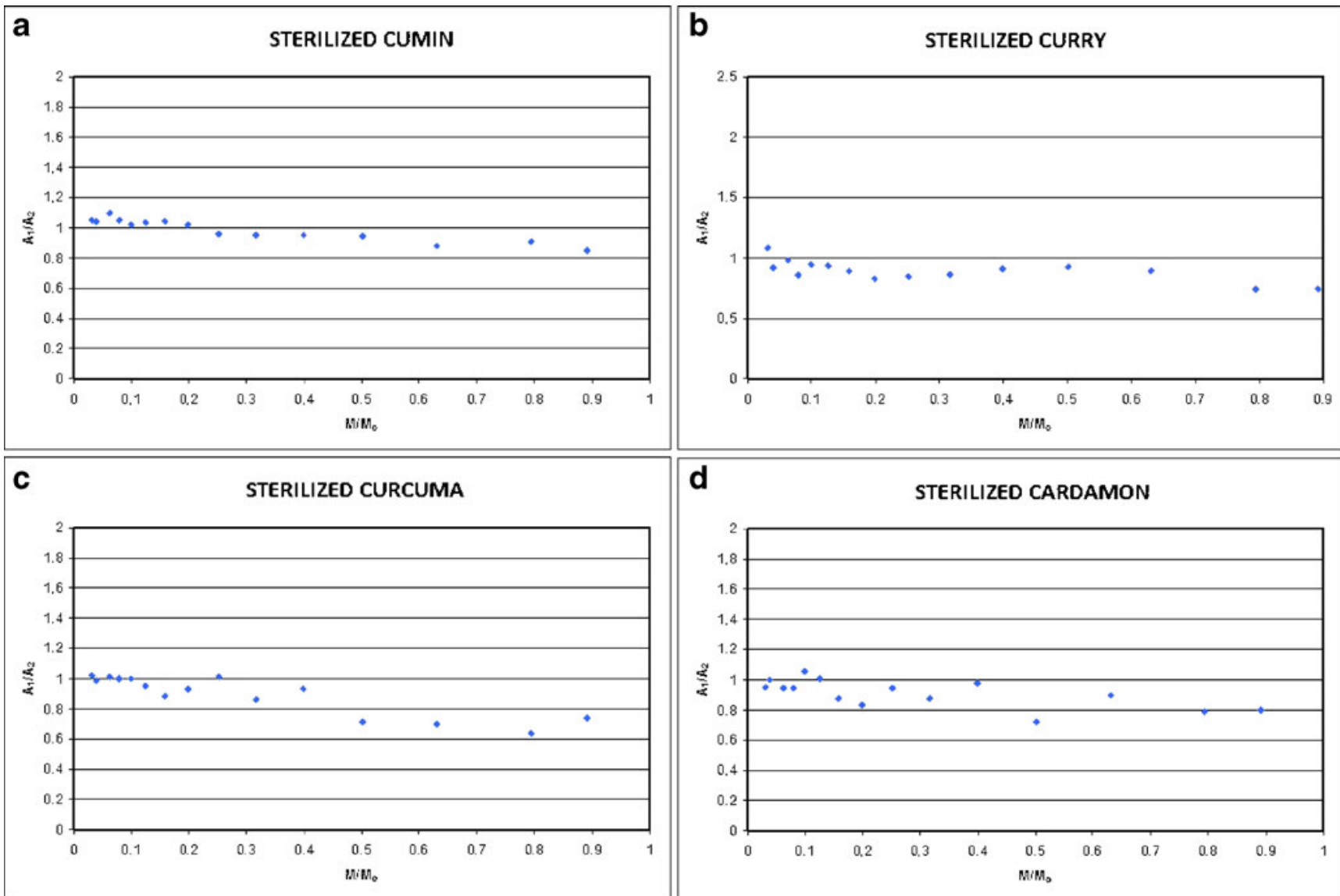

Fig. 7 The influence of microwave power $(M)$ on the lineshape parameter $A_{1} / A_{2}$ of caraway (a), curry (b), curcuma (c), and cardamom (d). $M_{0}$ $(70 \mathrm{~mW})$ is the total microwave power produced by klystron. The spectra were measured at room temperature 
and at the same microwave power. The concentration of the free radicals $(\mathrm{N})$ was calculated according to the formula:

$\mathrm{N}=\mathrm{N}_{\mathrm{u}}\left[\left(\mathrm{W}_{\mathrm{u}} \mathrm{A}_{\mathrm{u}}\right) / \mathrm{I}_{\mathrm{u}}\right] /[\mathrm{I} /(\mathrm{WAm})]$,

where:

$\mathrm{N}_{\mathrm{u}} \quad$ the number of paramagnetic center $(1.2 \times$ $10^{19}$ spin) in the ultramarine reference,

$\mathrm{W}$ and the receiver gains for sample and the

$\mathrm{W}_{\mathrm{u}} \quad$ ultramarine,

$A$ and the amplitudes of ruby signal for the sample and $\mathrm{A}_{\mathrm{u}} \quad$ the ultramarine,

I and $I_{u}$ the integral intensities for the sample and ultramarine,

$\mathrm{m} \quad$ the mass of the sample.

\section{Results}

EPR spectra were obtained for both the original and the sterilized herbs. The spectra of caraway (a), curry (b), curcuma (c), and cardamom (d) recorded with microwave power of $2.2 \mathrm{~mW}$ are presented in Fig. 3.
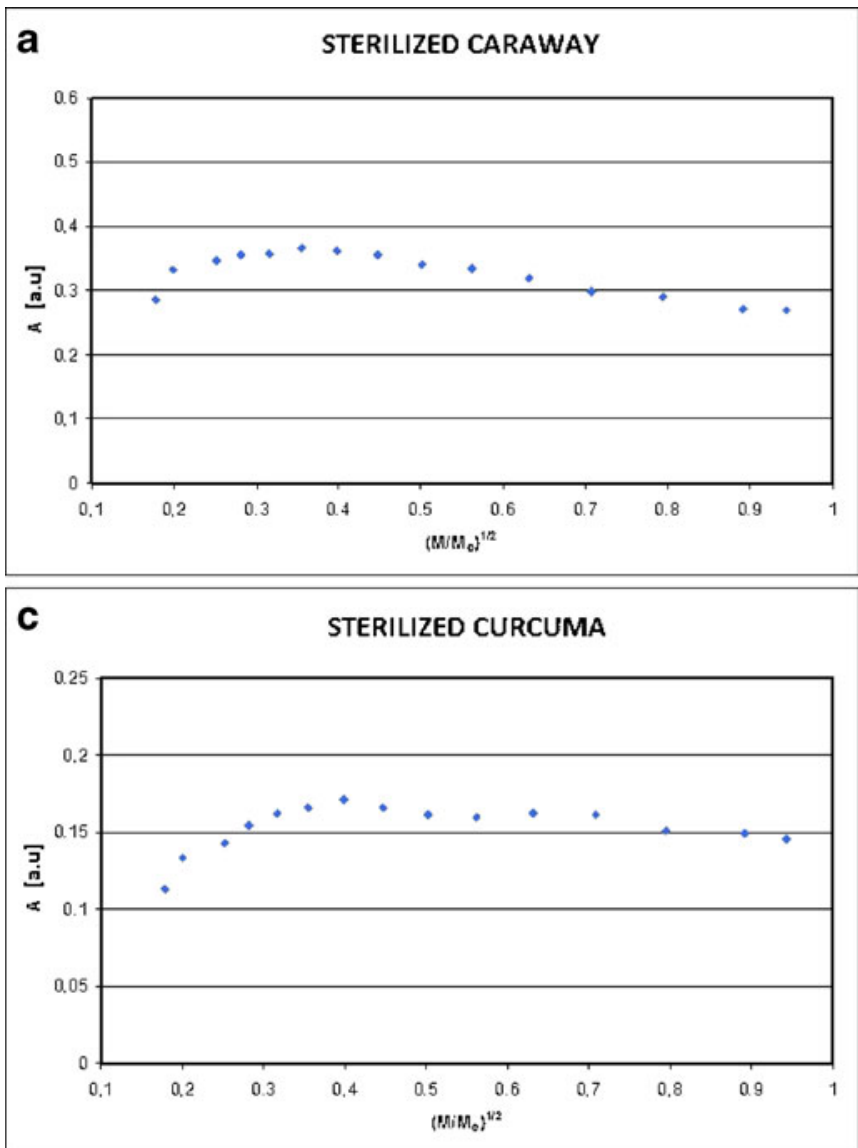

Sterilization process changes the EPR parameters of the studied herbs. $g$-Values, linewidths $\left(\Delta B_{p p}\right)$, and free radicals concentrations $(\mathrm{N})$ in the tested sterilized drugs are compared in Table 1 and in Figs. 4, 5, and 6.

Amplitude (A) of EPR lines of caraway decreases after sterilization, and its values increase after sterilization for curry, curcuma, and cardamom (Fig. 4). The linewidth $\left(\Delta \mathrm{B}_{\mathrm{pp}}\right)$ of EPR spectra of caraway, curry, and turmeric increase after sterilization of these herbs (Fig. 5). The linewidth $\left(\Delta \mathrm{B}_{\mathrm{pp}}\right)$ of EPR spectrum of cardamom decreases after sterilization of the sample (Fig. 5).

Free radicals concentration $(\mathrm{N})$ in all the tested herbs increase after sterilization (Fig. 6, Table 1). The highest free radical concentrations characterize caraway samples (Fig. 6, Table 1). The highest free radical formation during sterilization was observed for caraway and turmeric (Fig. 6, Table 1).

g-Values for the tested herbs were in the range of 1.9953 1.9973 (Table 1). The lowest g-values was obtained for curry 1.9953, and the highest g-values was obtained for caraway 1.9973 (Table 1).

The lineshape of the EPR spectra of all the tested samples changes with microwave power. The influence of microwave

\section{b STERILIZED CURRY}

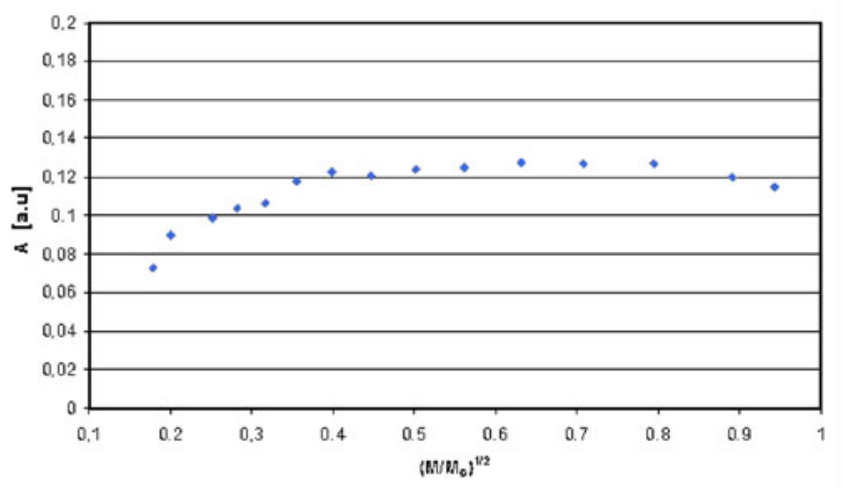

\section{d STERILIZED CARDAMON}

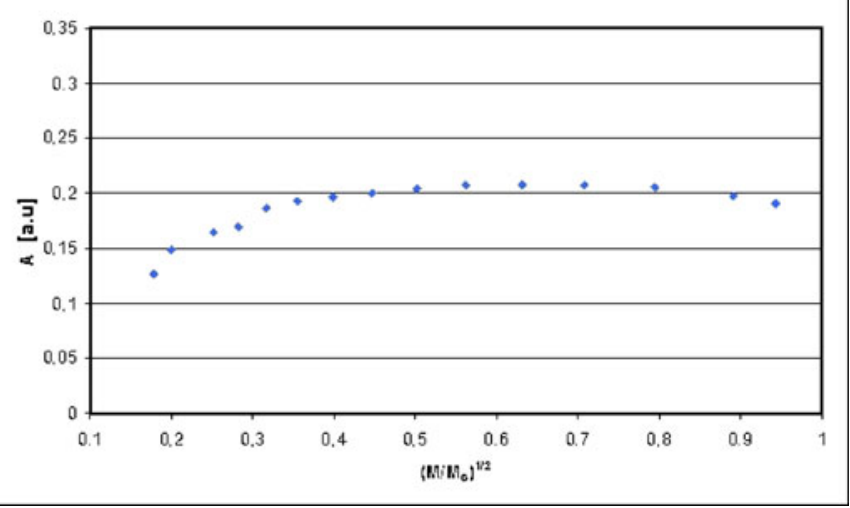

Fig. 8 The influence of microwave power (M) on amplitude (A) of EPR spectra of caraway (a), curry (b), curcuma (c), and cardamom (d). $M_{o}$ $(70 \mathrm{~mW})$ is the total microwave power produced by klystron. The spectra were measured at room temperature 
power (M) on the lineshape parameters $A_{1} / A_{2}$ of the EPR spectra is presented in Fig. 7.

The influence of microwave power on amplitudes (A) and linewidths $\left(\Delta \mathrm{B}_{\mathrm{pp}}\right)$ of the EPR spectra of the examined herbs is presented in Figs. 8 and 9, respectively. Amplitudes of the all recorded EPR spectra increase with increasing of microwave power (Fig. 8). The low increase of linewidths $\left(\Delta \mathrm{B}_{\mathrm{pp}}\right)$ of the EPR spectra was observed (Fig. 9).

\section{Discussion}

Application of electron paramagnetic resonance spectroscopy to examination of the popular herbs used in food pointed out their paramagnetic properties. All the studied herbs reveal EPR spectra (Fig. 3). Free radicals are responsible for the EPR curves. Existence of free radicals in herbs is not a positive effect, because of their toxic interactions with tissues in human organism. Free radicals initiate process of lipid peroxidation, which products are diamagnetic modified structures of cells [12]. Free radicals may be responsible for a lot of damages and diseases in tissues [12-16]. Free radicals cause cardiovascular disease, stroke, arthritis, diseases of the nervous system, diabetes and cancer [12-16].

The absence of free radicals formation should be taken into account during the production of herbs for food industry. The optimal method and conditions of the sterilization process should be found. The best herbs preparation should be accompanied by the lower formation of free radicals. This important technical problem of herb production was not tested and discussed so far. In this paper we proposed electron paramagnetic resonance spectroscopy as the helpful technique for the sterilization process of herbs in food industry. The main advantage of EPR spectroscopy is its conservative character relative to the examined sample. The applied in EPR magnetic fields with magnetic induction B about $331 \mathrm{mT}$ and microwaves with frequency of $9.3 \mathrm{GHz}$ are not destructive for the samples. The additional advantage of EPR spectroscopy is the low amount of the samples which is located in the resonance cavity of the spectrometer. EPR method brings to light information about properties and free radicals concentration in the samples $[10,11]$.

The stabile amount of free radicals was found in the examined herbs. The amplitudes (Fig. 4) and linewidths (Fig. 5) of the free radicals in the tested herb samples are

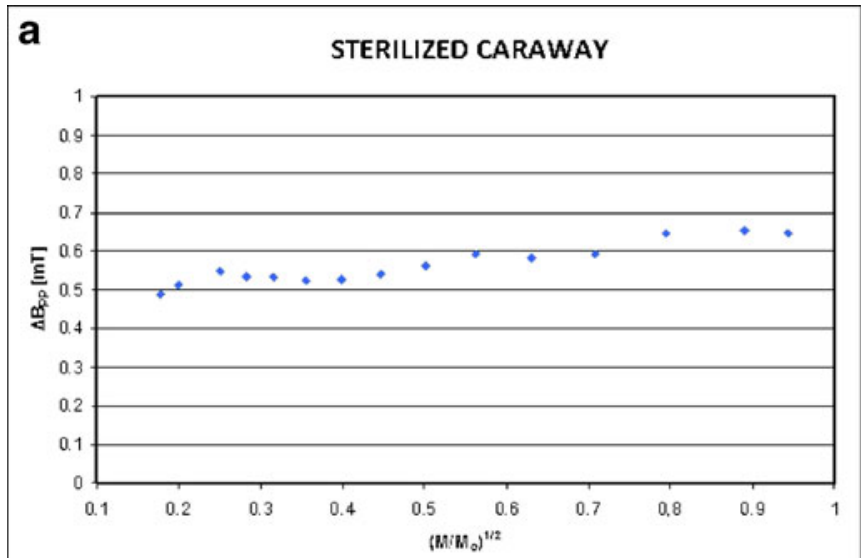

b
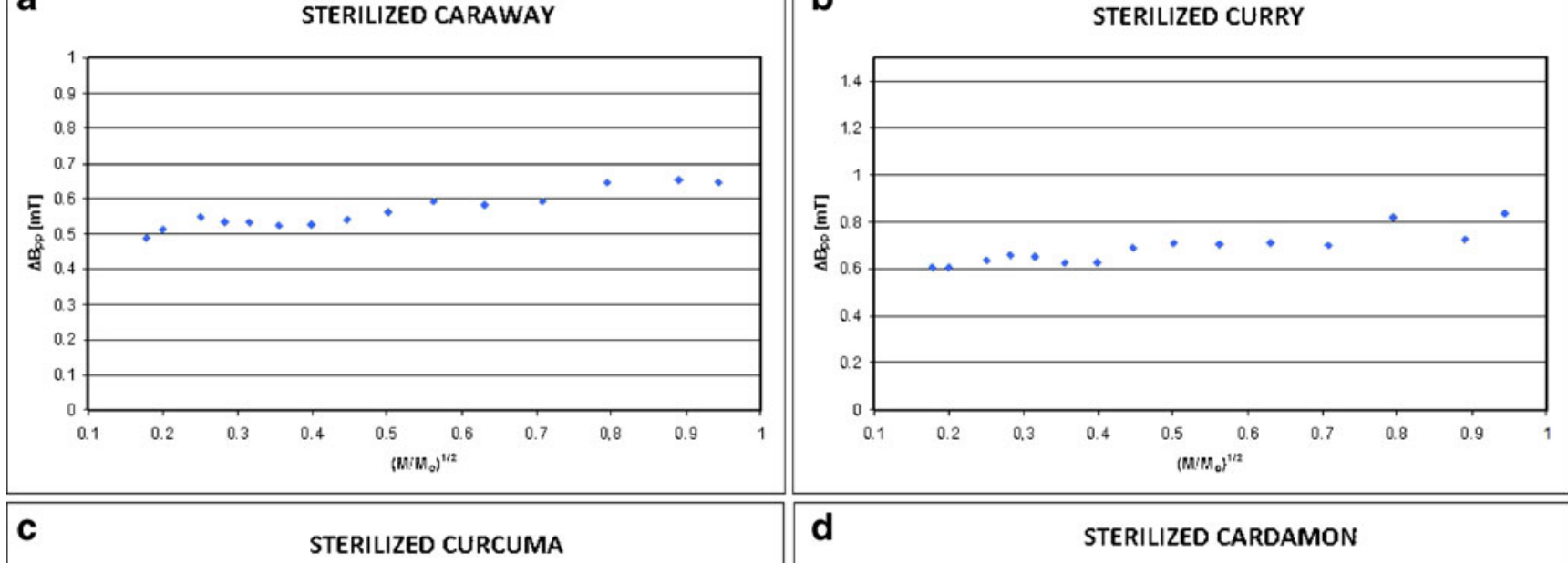

d

STERILIZED CARDAMON
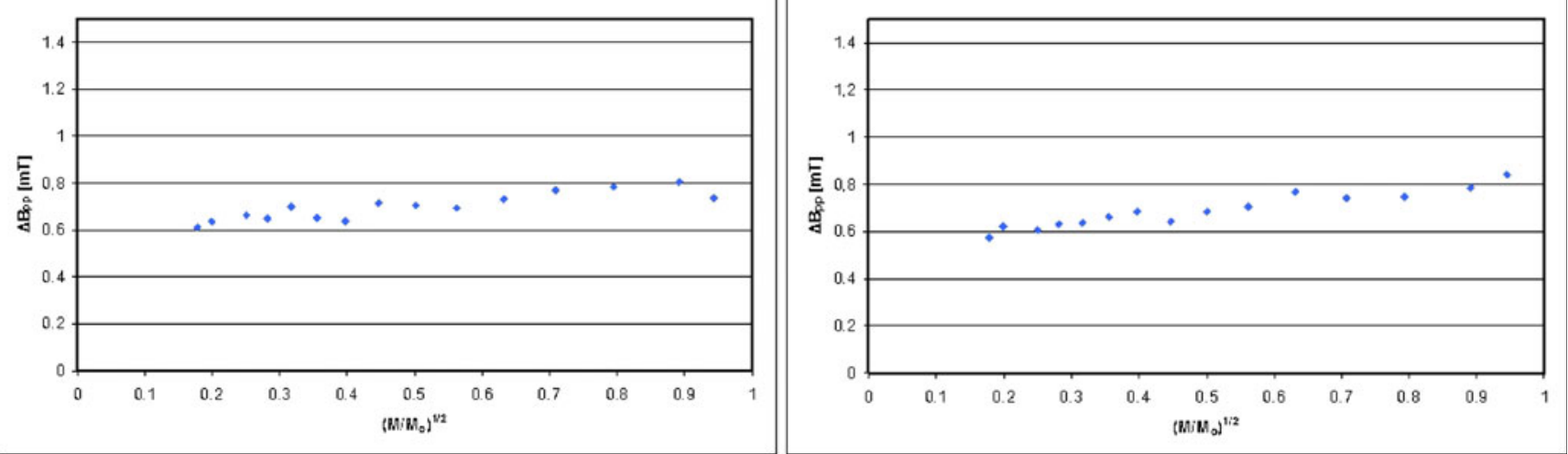

Fig. 9 The influence of microwave power (M) on linewidth $\left(\Delta \mathrm{B}_{\mathrm{pp}}\right)$ of EPR spectra of caraway (a), curry (b), curcuma (c), and cardamon (d). $\mathrm{M}_{\mathrm{o}}$ $(70 \mathrm{~mW})$ is the total microwave power produced by klystron. The spectra were measured at room temperature 
different. Free radicals in concentrations about $10^{18} \mathrm{spin} / \mathrm{g}$ exist in caraway, curry, curcuma, and cardamom, before and after sterilization (Table 1, Fig. 6). The similar order of free radicals concentrations characterize the non- and sterilized herb samples (Table 1, Fig. 6). The low differences between free radical concentrations in the original samples and sterilized samples indicate the proper sterilization method was chose for caraway, curry, curcuma, and cardamom.

The highest free radical content was obtained for caraway (Table 1, Fig. 6). It is only hoped that free radicals of the caraway are not very reactive one. It should be stressed that these free radicals are not formed during the sterilization process, but they are mainly the feature of the original herb material. The other studied herbs, such as curry, curcuma, and cardamom, reveal the relatively lower free radicals contents (Table 1, Fig. 6). So the relatively weaker free radical toxic effects are expected during their use in organism.

EPR spectroscopy showed the properties of the free radicals in the studied herbs. Similar properties of the original and sterilized herbs were shown. Free radicals in the original and sterilized caraway, curry, curcuma, and cardamom are the complex system consisting of several types of free radicals. Because of the g-values in the range of 1.953-1.973 (Table 1), it is expected that oxygen and carbon free radicals mainly exist in the tested herbs. The changes of the lineshape of the EPR spectra and the tested linespahe parameter $\mathrm{A}_{1} / \mathrm{A}_{2}$ (Fig. 7) proved the existence of different types of free radicals in the caraway, curry, curcuma, and cardamom.

Free radicals are homogeneously distributed in all the tested herbs. It is confirmed by the character of changes of amplitudes (Fig. 8) and linewidths (Fig. 9) with microwave power. Amplitudes of the examined EPR lines increase with increasing of microwave power, reach the maximum, and then they begin to decrease (Fig. 8). The linewidths increase with increasing of microwave power (Fig. 9). These two correlations (Figs. 8 and 9) describe free radicals homogeneously distributed in the samples [10]. Homogeneous distribution of free radicals in sterilized caraway, curry, curcuma, and cardamom (Figs. 8 and 9) indicates the properly performed sterilization process with the homogeneous interactions of the sterilization factor in the whole volume of the herb samples. In this work continuous microwave saturation of EPR spectra was used in these kinds of tests.

The saturation of the EPR lines of the tested herbs, nonand sterilized, (Fig. 8) pointed out that slow spin-lattice relaxation processes exist in the examined samples. The broad EPR spectra, the high values of linewidths (Table 1, Fig. 9), are characteristic for strong dipolar interactions between free radicals in the samples [10]. Dipolar interactions increase with decreasing of distances between unpaired electrons of paramagnetic centers [10]. The short distances between free radicals exist in both the original and sterilized caraway, curry, curcuma and cardamom. The high density of free radicals in the tested herbs shows probability of their strong interactions with paramagnetic oxygen molecules [10]. It is expected that oxygen molecules will link with free radicals of the herbs via so called quasichemical bonds [10].

The performed studies confirmed usefulness of electron paramagnetic resonance spectroscopy in examination of the sterilization products in technology of herbs production. These studies of herbs may be done in laboratories of medical or technical universities, but practically it is expected that in the future they will be performed by engineers in the industrial plant. The industrial studies may be done by the use of the EPR spectrometer with the low dimensions electromagnet as the source of magnetic field. The EPR method is proposed by us as the additional one to chemical studies of the sterilized herbs.

\section{Conclusions}

Electron paramagnetic resonance studies of the herbs pointed out that:

1. Free radicals $\left(\sim 10^{18} \mathrm{spin} / \mathrm{g}\right)$ exist in both the original and sterilized caraway, curry, curcuma, and cardamom.

2. EPR studies confirmed that the method and conditions of sterilization of the tested herbs were chosen properly, because free radical properties and concentrations in the original and sterilized samples were similar. Steam sterilization produces only the low amount of free radicals.

3. Complex free radical system characterizes both original and sterilized examined herbs. Oxygen and carbon free radicals mainly exist in the tested herbs.

4. Continuous microwave saturation of EPR spectra pointed out that free radicals are homogeneously distributed in the tested herbs.

5. Strong dipolar interactions and slow spin-lattice relaxation processes exist in the examined original and sterilized herbs.

Acknowledgments This study was supported by Medical University of Silesia in Katowice, the grants no. KNW-1-126/10.

Open Access This article is distributed under the terms of the Creative Commons Attribution License which permits any use, distribution, and reproduction in any medium, provided the original author(s) and the source are credited.

\section{References}

1. M. Borucha, B. Król, Procesy technologii żywności (Politechnika Łódzka, Łódź, 1993)

2. H.F. Kayser, A.K. Beienz, J. Ecker, M.R. Zinkernagel, Mikrobiologia lekarska (Wydawnictwo Lekarskie PZWL, Warszawa, 2007) 
3. P. Ramos, Wolne rodniki w wybranych antybiotykach aminoglikozydowych i $\beta$-laktamowych sterylizowanych termicznie. Praca doktorska, Katowice, Poland: Śląski Uniwersytet Medyczny w Katowicach. (2009)

4. P. Ramos, B. Pilawa, The EPR examination of free radicals formation in thermally sterilized $\beta$-lactam antibiotics. Curr. Top. Biophys. 33, 183-187 (2010)

5. S. Wilczyński, Właściwości wolnorodnikowe wybranych gamma napromieniowanych antybiotyków. Praca doktorska, Katowice, Poland: Ślaski Uniwersytet Medyczny w Katowicach. (2008)

6. P. Ramos, B. Pilawa, Effect of temperature and time of thermal sterilization on formation of free radicals in isosorbide dinitrate. Farm. Przegl. Nauk. 5, 28-33 (2010)

7. K. Pawłowska-Góral, E. Kurzeja, B. Pilawa, P. Ramos, EPR studies Rhizoma calami. Eng. Biomater. 12(159-161) (2009)

8. M. Mazik, M. Pastwa, Atlas ziót. Medycyna naturalna, kuchnia, kosmetyka (Wydawnictwo Dragon, Warszawa, 2010)

9. Rumińskiej, A. Ożarowski, Leksykon roślin leczniczych (Państwowe Wydawnictwo Rolnicze i Leśne, Warszawa, 1990)
10. J.E. Wertz, J.R. Bolton, Electron Spin Resonance Theory and Practical Applications. New York, London. (1986)

11. G.R. Eaton, S.S. Eaton, K.M. Salikhov, Foundations of modern EPR (World Scientific, Singapore, New Jersey, London, Hong Kong, 1998)

12. G. Bartosz, Druga twarz tlenu (Wydawnictwo Naukowe PWN, Warszawa, 2004)

13. C. Vergely, Role of free radicals in the cardiac adaptation to ischemia-reperfusion injury. Studies with electron paramagnetic resonance spectroscopy. Cardiovascular diseases. Free Radic. Biol. Med. 5, 149 (2002)

14. D. Parkinson, Oxygen free radicals: in search of a unifying theory of disease. Int. Crit. Care Nurs. 11, 336-340 (1995)

15. S. Milam, G. Zardeneta, J. Schmitz, Oxidative stress and degenerative temporomandibular joint disease: a proposed hypothesis. J. Oral. Maxillofac. Surg. 56, 214-223 (1998)

16. Salas, J. Panes, J.I. Elizalde, M. Casadevall, D.N. Granger, A. Josep, M. Pique, Diabetes exacerbates free radical production in response to splanchnic ischemia/reperfusion: mechanisms and cellular origin. Gastroenterology 114, 4 (1998) 